\title{
Academic Procrastination: Relationships with Support from the Environment and Self-Leadership
}

\author{
Tais Guedes de Melo ${ }^{1}$ \\ Helenides Mendonça ${ }^{1}$
}

\begin{abstract}
Procrastination is the behavior related to voluntary delays at the beginning or end of tasks and in decision making. The aim of this study was to evaluate the mediational effect of self-leadership strategies on the relationship between academic procrastination and support from the environment. A cross-sectional correlational study was carried out with the participation of 1,436 students. Three instruments were used: Learning Support Scale, Academic Procrastination Scale - Short Form and Revised Self-Leadership Questionnaire. The findings confirmed the hypotheses by demonstrating that the more students use self-leadership strategies, the less they procrastinate and the lesser the influence of support from the environment. The full mediation model has been confirmed. The study stands out for its understanding of procrastination and the influence of support from the environment and self-leadership. It is suggested that further longitudinal studies be conducted, assessing differences in these behaviors between groups of students, programs, levels of higher education or shifts.
\end{abstract}

Keywords: social support, procrastination, leadership

\section{Procrastinação Acadêmica: Relações com o Suporte do Ambiente e Autoliderança}

\begin{abstract}
Resumo: Procrastinação é o comportamento relacionado aos atrasos voluntários nos inícios ou términos de tarefas e nas tomadas de decisão. O objetivo deste estudo foi avaliar o efeito mediacional das estratégias de autoliderança na relação entre procrastinação acadêmica e suporte do ambiente. Foi realizado um estudo correlacional de corte transversal que contou com a participação de 1.436 estudantes. Foram utilizados três instrumentos: Escala de Suporte à Aprendizagem, Academic Procrastination Scale - Short Form e Revised Self-Leadership Questionnaire. Os achados confirmaram as hipóteses ao demonstrarem que quanto mais eles utilizam estratégias de autoliderança menos eles procrastinam e menor é a influência do suporte ambiental. O modelo de mediação total foi confirmado. A pesquisa destaca-se pela compreensão da procrastinação e a influência do suporte do ambiente e da autoliderança. Sugere-se a realização de estudos longitudinais, que avaliem diferenças desses comportamentos entre grupos de estudantes, cursos, níveis de ensino superior ou turnos.
\end{abstract}

Palavras-chave: apoio social, procrastinação, liderança

\section{Procrastinación Académica: Relaciones con el Soporte del Ambiente y Autolideranza}

\begin{abstract}
Resumen: La procrastinación es el comportamiento relacionado con retrasos voluntarios al comienzo o al final de las tareas y en la toma de decisiones. El objetivo de este estudio fue evaluar el efecto mediador de las estrategias de auto-liderazgo en la relación entre la procrastinación académica y el apoyo del entorno. Se realizó un estudio correlacional transversal con la participación de 1436 estudiantes. Se utilizaron tres instrumentos: Escala de apoyo al aprendizaje, Academic Procrastination Scale - Short Form y Revised Self-Leadership Questionnaire. Los hallazgos confirmaron las hipótesis al demostrar que cuanto más utilizan las estrategias de autoliderazgo, menos procrastinan y menor es la influencia del apoyo ambiental. Se ha confirmado el modelo de mediación completo. La investigación se destaca por su comprensión de la procrastinación y la influencia del apoyo ambiental y el autoliderazgo. Se sugiere realizar estudios longitudinales, que evalúen diferencias en estos comportamientos entre grupos de estudiantes, cursos, niveles de educación superior o turnos.
\end{abstract}

Palabras clave: apoyo social, procrastinación, liderazgo

${ }^{1}$ Pontificia Universidade Católica de Goiás, Goiânia-GO, Brazil

Article derived from a master's thesis by the first author under supervision by the second author, defended in 2017, in the Graduate Program in Psychology of Pontifícia Universidade Católica de Goiás.

Correspondence address: Tais Guedes de Melo. Pontifícia Universidade Católica de Goiás. Praça Universitária, 1440, Setor Universitário, GoiâniaGO, Brazil. CEP 74.605-010. E-mail: taiscoach@gmail.com
Procrastination consists of behaviors that implicate delays at the beginning or end of tasks or decision-making with deadlines established by the person or by third parties (Ferrari, Harriott, Evans, Lecik-Michna, \& Wenger, 1997; Visser, Korthagen, \& Schoonenboom, 2018). It presents itself as an 
integral part of the routine of many Brazilians, especially in the university context (Geara, Hauck Filho, \& Teixeira, 2017). It is a phenomenon that has concerned many researchers, as it affects one out of every four adults (Ferrari et al., 1997; Hen \& Goroshit, 2018; Visser et al., 2018).

As from the 1980s, psychology began to study procrastination, characterizing it as a voluntary postponement of a desired activity, even if it is necessary or important for the procrastinator or if it has negative consequences resulting from the postponement of a task (Klingsieck, 2013; Ribeiro, Avelino, Colauto, \& Casa Nova, 2014). The act of procrastinating does not correspond to an individual's idleness, but it occurs for less relevant reasons (Klingsieck, 2013).

Research has shown that the lack of planning and task monitoring and ineffective organizational strategies are common self-regulation problems experienced by procrastinators (Visser et al., 2018). In contrast, research that correlates self-regulation or self-efficacy with procrastination has shown that individuals who procrastinate less have strategies to control and organize events in their lives (Balkis \& Duru, 2016; Job, Walton, Bernecker, \& Dweck, 2015; Kadzikowska-Wrzosek, 2018; Rebetez, Rochat, Barsics, \& Van Der Linden, 2016; Vohs \& Baumeister, 2004). By analogy, it is believed that selfleadership can influence procrastinating behavior, since, based on the theory of self-regulation, it consists of one's confidence in his/her personal ability to organize and execute certain actions, producing motivation, cognitive processing and courses of action necessary to exercise control over events in life (Bandura, 1977). Even if studies do not directly address the relationship between selfleadership and procrastination, it is possible to infer that this strategy can reduce procrastinating behavior.

Self-leadership strategies are a process of behavioral self-influence that results in better performance and helps in defining what to do (for example, setting standards and goals), why to do it (for example, strategic analysis) and how to do it (for example, strategic implementation) (Neck, Manz, \& Houghton, 2019). Considering this significant influence that self-leadership has on students' and workers' performance, the interest of scientific studies on this subject has grown considerably in recent years (Neck \& Houghton, 2006; Neck \& Manz, 2013; Neck et al., 2019).

The present study was based on the social cognitive theory, which defines the learning process through the continuous interaction of individuals, behavior and the environment. It states that people learn when they are motivated by the recognition of their success as apprentices, as well as when they observe other people's performance (Bandura, 1977). It reinforces their beliefs in their own capacity (self-efficacy), which reflects on the way they control their own functioning, their experience and reactions to life events and their selfregulation (Bandura, 1977; Ryan \& Deci, 2000).

Given the information described above, the present study proposes answering the following empirical questions: how can support from the environment influence the behavior of academic procrastination?, and; how does self- leadership mediate the relationship between support from the environment and academic procrastination?.

Even academics who need to improve their self-regulatory strategies will possibly be able to act as agents of change in their own academic life. Personal tools and environmental resources are important for academics, as they can facilitate planning, anticipation, monitoring and self-intervention in their actions and thoughts (Bandura, 1977). The aim of this study was to evaluate the mediational effect of behaviorfocused self-leadership strategies on the relationship between support from the environment and academic procrastination. Furthermore, it seeks to understand the influence of learning support on procrastination, considering the aspects related to direct or indirect effects, when shaped by self-leadership, in the dimension of behavior-focused self-leadership strategies. These relationships are shown in Figure 1.

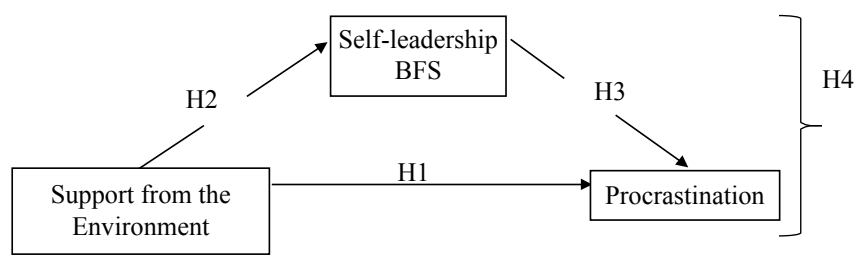

Figure 1. Conceptual hypothetical model.

In line with the proposed objective, when analyzing the role played by support from the environment in avoiding academic procrastination, the new findings will contribute to knowledge about the beneficial effects of behavior-focused self-leadership strategies and how such variable affects the relationship between support from the environment and academic procrastination.

Students will be able to have more autonomy and fewer procrastination behaviors if they associate meanings with the content learned. This process is referred to as meaningful learning, which can influence the process of performing tasks, contributing to their learning process. Students may be able to learn new things when they relate them to previous experiences, acquired knowledge, beliefs and representations (Ribeiro et al., 2014).

Learning support is perceived in the dimensions of support provided by colleagues, managers and support environments in relation to the application of knowledge and skills acquired in the learning environment. Support from the environment includes characteristics of teachers' roles as supervisors and learning support agents, of the results from the feedback from peers and colleagues in the environment and of individuals' support provision (Coelho Junior, da Silva Abbad \& de Lira Todeschini, 2005 ). The focus of this study is on learning support, specifically in the environmental dimension, which involves the interactions between teachers and colleagues as a context variable that may negatively influence the academic procrastination behavior. Thus, the investigative hypothesis (H1) that support from the environment is negatively associated with academic procrastination is established. 
Learning support provides external stimuli to individuals in the spontaneous learning process through contact with colleagues/peers who have more knowledge, self-teaching or imitation behavior. These are support dimensions, such as the creation of positive expectations about the benefits of learning and its application, the provision of feedback and the dissemination of information related to competent performance (Coelho Junior, da Silva Abbad \& de Lira Todeschini, 2005)

Studies have shown that individuals who receive support from the environment can make changes in their immediate world, behaving in a desirable way, through behaviorfocused strategies (Manz et al., 2016). Many of these changes are simple, but can make a real difference in one's actions. Therefore, it is coherent to assume that as students manage to develop behavior-focused self-leadership strategies, they will possibly increase their self-awareness and motivation necessary to perform tasks that, although important for the success of an enterprise (in a broad sense), can be considered unpleasant or intrinsically not motivating (Manz et al., 2016). Given these findings, the hypothesis (H2) that support from the environment is positively associated with behaviorfocused strategies (BFS) is postulated.

Behavior-focused self-leadership strategies identify and expand the quality and quantity of desirable behaviors, while identifying and decreasing the incidence and/ or severity of undesirable behaviors, in order to build, maintain and/or improve individual performance as well as performance levels (Manz et al., 2016). Studies have shown that a natural focus on rewards or on activity aspects is more motivating, as it encourages individuals to develop tasks with more excellence, even those that are less desirable (Rebetez et al., 2016).

With this regard, behavior-focused strategies (BFSs) can contribute to avoid procrastination, as they are strategies that aim to increase the degree of knowledge, both of one's own behavior and of task performance, thus facilitating the necessary individual attitudinal regulation for such performance (Manz et al., 2016). BFSs are defined in five behavioral dimensions: self-observation, self-goal setting, self-reward and self-feedback for self-correction and selfsupport (Neck \& Manz, 2013; Manz et al., 2016).

The self-observation process can be useful to identify relevant situations that will support behavioral management by analyzing the need to improve or suppress a certain attitude, in view of how it affects an individual's performance. This process of self-observation can be aligned with goal setting, where these behaviors perform as an individual reward system, assuming an energizing role in individual performance (Neck \& Houghton, 2006; Manz et al., 2016).

Goal setting, aligned with purpose, can be enhanced with the third dimension of behavior-focused strategies, selfreward, that is, the positive influence of actions through the setting of rewards for the desired and adopted behaviors at the physical and mental levels (Neck \& Houghton, 2006; Manz et al., 2016). Individuals will be able to significantly improve their own behaviors, if they intentionally seek behaviors that they aim for and reward themselves with positive and self-motivating words and images for each successful action (Manz et al., 2016).

In addition, self-feedback practices can eliminate ineffective behaviors or those that do not contribute much to performance or goal pursuit (Neck \& Houghton, 2006). There is also an important dimension of this strategy in the literature, which is self-cueing to adjust behavior, that is, target identification can contribute to fixing important aspects related to function, enhancement of behaviors and more effective thoughts and reduction of other more destructive ones when performing tasks (Neck \& Houghton, 2006; Manz et al., 2016). Based on these notes on the dimensions of these strategies, the investigative hypothesis (H3) that behavior-focused self-leadership strategies are negatively associated with academic procrastination is established.

Beyond the investigation on the association between support from the environment and academic procrastination, self-leadership is a variable of significant importance for analyzing and understanding the procrastination behavior of university students. It is understood that a relevant part of the study is data collection and analysis, resulting in the best interpretation of how self-leadership mediation will occur between support from the environment and academic procrastination behavior.

The literature review showed the great plurality of interpretations about procrastination, permeating the field of study with different definitions and theoretical approaches. Analogously to self-regulation, self-leadership is positively correlated with academic procrastination, and it can be prevented or controlled by self-leadership strategies (Ferrari et al., 1997; Grunschel, Patrzek, Klingsieck, \& Fries, 2018; Vohs \& Baumeister, 2004). Thus, the aim of this study was to evaluate the mediational effect of self-leadership strategies on the relationship between academic procrastination and support from the environment.

Based on such considerations, hypothesis (H4) was formulated: the relationship between support from the environment and academic procrastination is mediated by behavior-focused self-leadership strategies.

\section{Method}

This was a cross-sectional correlational study conducted with university students from different programs in public and private institutions.

\section{Participants}

One thousand, four hundred and thirty-six university students from the Midwestern region of Brazil participated in the study, of whom $51.8 \%$ were females, and $48.2 \%$ were males. Their mean age was 24.8 years $(S D=10.86)$, and $76.1 \%$ had jobs. Of such participants, $84 \%$ were majoring in Applied Social Sciences, $7.4 \%$ in Engineering, 3.6\% in 
Humanities, 3.5\% in Linguistics, Languages and Arts, and $1.5 \%$ in Health Sciences. Most of the students surveyed were in the initial stage of their undergraduate program $(n=44 \%)$, and the remaining participants were in the middle $(n=40.9 \%)$ and at the end of their programs $(n=15.1 \%)$.

\section{Instruments}

Academic Procrastination Scale - Short Form (APS-S) (Yockey, 2016) and Revised Self-Leadership Questionnaire (RSLQ) (Houghton \& Neck, 2002). These instruments were translated according to standards by the International Testing Commission and their due procedures. The English version was translated into Portuguese by two independent bilingual translators and then back translated, which also occurred independently. The two translated versions were synthetized by a referee with the purpose of achieving a single version of the instruments. Equivalence between the translated versions and the original instruments was maintained in order to ensure semantic, idiomatic, experiential and conceptual correspondences. Some of the items needed to be reformulated so that their clarity could be ensured.

Support from the environment. In order to evaluate support from the environment, the Learning Support Scale was used (Coelho Junior, da Silva Abbad \& de Lira Todeschini, 2005). The original measure consists of a fivepoint likert-type scale, ranging from 1-never to 5-always occurs. The scale has 31 items $(\alpha=0.98)$, and it is structured on two factors: support from the teacher and support from the environment. For this study, only the support-from-theenvironment dimension, with 13 items $(\alpha=0.88)$, was used, since it explains an individual's perception of the support received by the work unit, by management in relation to his/her learning and of the application of new knowledge and skills informally acquired in work situations. Aiming to reach the objective of the study, the Learning Support Scale was adapted to the academic context. For that purpose, some items were modified so that they could refer to the classroom environment. For example, terms such as "management support" were replaced by "teacher support", "in my work sector" by "in my classroom" and "co-workers" by "classmates". Another example of item modification refers to the original item "In my work sector, each member is encouraged to state what he/she thinks". In this study, this item was adapted to "In my classroom, each student is encouraged to state what he/she thinks". The adaptation was justified by the need to analyze the influence from the context variable, which consists of teacher support, an environment of support from classmates in the process of academic procrastination. The incipience of instruments for such evaluation led us to understand that the Learning Support Scale was appropriate for modifying the wording of items in order to reach the objective of the study without changing the consistency or the essence of the terms. To that end, a confirmatory factor analysis was performed, in which goodness-of-fit was achieved, with a
Cronbach's Alpha ranging from 0.52 to 0.80 (GFI $=0.975$; AGFI $=0.958$; TLI $=0.959$; CFI $=0.971$ and RMSEA $=$ 0.049 ), preserving all items related to support from the environment.

Academic Procrastination. The instrument Academic Procrastination Scale - Short Form (APS-S), developed by Yockey (2016), was used, the validation of which resulted in good reliability estimates. The original measure consists of a five-point likert-type scale, ranging from 1-totally disagree to 5-totally agree. The scale consists of five items $(\alpha=0.85)$, reduced to one factor. Two items that allow representing this scale are: "I postpone projects until the last minute" and "I get distracted by other more interesting things, when I should be performing school activities" (Yockey, 2016). A confirmatory factor analysis was performed, in which goodness-of-fit was achieved (GFI $=0.995$; AGFI $=0.984$; $\mathrm{TLI}=0.946$; CFI $=0.973$ and $\mathrm{RMSEA}=0.045)$, preserving all the items on the scale.

Self-leadership. Self-leadership analysis was performed using the Revised Self-Leadership Questionnaire (RSLQ) by Houghton and Neck (2002). The original measure consists of a five-point likert-type scale, ranging from 1-totally disagree to 5-totally agree. The Revised Self-Leadership Questionnaire (RSLQ) is composed of nine first-order dimensions and three second-order dimensions. In this study, only a secondorder dimension was used: Behavior-Focused Strategies (BFS). The BFS dimension seeks to increase individuals' self-awareness, motivating them to perform tasks considered unpleasant or not intrinsically motivating. An example of an item that represents this dimension is: "I consciously have goals in mind for my work efforts". The confirmatory factor analysis in the original study resulted in a reduced dimension to five items (Houghton $\&$ Neck, 2002). And the same analysis carried out in this study showed goodness-of-fit for the seven-item reduced dimension $(\mathrm{GFI}=0.984$; AGFI $=0.968$; $\mathrm{TLI}=0.968$; $\mathrm{CFI}=0.979$ and RMSEA $=0.059$ ).

Control Variables. The questionnaire used in this study contained sex, age and whether the individual currently had a job as control variables. Sex was measured as a binary measure ( 1 for male and 2 for female); whether the participant had a job was also identified using a binary measure ( 1 for yes and 2 for no). Age was obtained through the interval measure informed by the participants and structured through categories.

\section{Procedures}

Data collection. Data collection was carried out in person by making questionnaires available together with the informed consent term, which was intended to inform respondents about the study objectives, the guarantee of confidentiality of their responses and that participation was voluntary. Access to the questionnaire was only allowed for students who agreed to participate in the study, after due 
clarification. Questionnaire completion did not take more than 20 minutes.

Data analysis. All collected data, represented by numerical indicators, were analyzed by the Statistical Package of Social Science (SPSS) software, version 21.0, Process and Amos 21.0.

As for the normality of the distributions, the asymmetry and kurtosis values were evaluated according to the parameters indicated by Miles and Shevlin (2001), and all variables met the requirements. The factors analyzed in the model, such as homoscedasticity and linearity of the regression model, were analyzed by regression residuals. Multicollinearity analysis was performed using the Variance Inflation Factor and Tolerance indices. To examine the discriminant validity of the measurements, a set of confirmatory factor analyses (CFA) was performed using AMOS 21.0, utilizing the maximum likelihood estimation method.

Correlations between the study variables were performed. As this study used only one data source, common-variance analysis between the constructs was carried out (Podsakoff, MacKenzie, \& Podsakoff, 2012). The general fit of the model was evaluated considering the following indicators: Comparative Fit Index - CFI; Goodness-of-Fit Index - GFI; and Root Mean Square Error of Approximation - RMSEA. According to Browne and Cudeck (1993), the model is considered adequate when the $\chi 2 /$ Gl ratio is less than 3 , CFI and GFI show coefficients equal to or greater than 0.90 , or when obtaining RMSEA values below 0.10 . Following the recommendations by Podsakoff et al. (2012), a three-factor model test (support from the environment, behavior-focused strategies and academic procrastination) was performed, including the latent variable, method.

A set of regression models using Process (Preacher \& Hayes, 2008) was applied to test the mediational effect of self-leadership (mediating variable) on the relationship between support from the environment (predictor variable) and academic procrastination (dependent variable). To that end, model 4 was used, which made it possible to test each path described in Figure 1. The estimates presented are based on 5,000 bootstrap samples. The effects were estimated using $95 \%$ of the confidence intervals. In addition, each equation was controlled for sex, age and whether the individuals currently worked.

\section{Ethical Considerations}

The study was approved by the Ethics and Research Committee of Pontifícia Universidade Católica de Goiás (CAAE No. 66228217.8.0000.0037), taking into account the following ethical aspects: participants' consent; confidentiality and anonymity; communicating to participants the benefits obtained from the study, preserving the study participants' image and self-esteem; intellectual property of result dissemination data; offering resources to deal with possible research risks, the possibility of referral to therapy at the CEPSI (Centro de Pesquisa e Práticas Psicológicas) of Pontifícia Universidade Católica de Goiás. The action strategies listed for the development of this study are based on the knowledge of and compliance with legal, ethical, scientific and bioethical requirements necessary for research with human beings, according to Resolution 510/16.

\section{Results}

When performing the three-factor model test (support from the environment, behavior-focused strategies and academic procrastination), with the latent variable, method, the following were obtained as fit indexes GFI $=0.962$; $\mathrm{AGFI}=0.953 ; \mathrm{TLI}=0.962 ; \mathrm{CFI}=0.966$ and $\mathrm{RMSEA}=0.034$. According to the indexes by Podsakoff et al. (2012), it was shown that the common bias of the method did not represent a threat to results.

\section{Descriptive Statistics}

Support from the environment, academic procrastination and behavior-focused strategies were significantly associated. The results of descriptive correlation analyses showed that support from the environment was positively associated with behavior-focused self-leadership strategies (BFS) and negatively associated with academic procrastination $(r=0.23 ; p \leq 0.01 ; r=-0.08, p \leq 0.01$; respectively $)$. Behaviorfocused self-leadership strategies were negatively related to academic procrastination $(r=-0.26 ; p \leq 0.01)$. These data supported hypotheses $\mathrm{H} 1, \mathrm{H} 2$ and $\mathrm{H} 3$. The studied variables obtained the following means and standard deviations: support from the environment $(M=3.36, S D=0.66)$, self-leadership - BFS $(\mathrm{M}=3.96, S D=0.72)$ and academic procrastination $(M=2.09, S D=0.97)$.

\section{Hypothesis Test}

Hypothesis 1 predicted that support from the environment (I.V.) was negatively associated with academic procrastination (D.V.). As shown in Table 1, support from the environment was negatively associated with academic procrastination, after controlling for age, sex and whether currently holding a job $\left(\mathrm{b}=-0.14, \mathrm{t}_{(1436)}\right.$ $=-3.59, p=0.000$ ). Thus, hypothesis 1 was supported by the data. Support from the environment (I.V.) was positively associated with behavior-focused selfleadership strategies (Mediating Variable) $\left(\mathrm{b}=0.26, \mathrm{t}_{(1436)}=\right.$ $9.33, p=0.000$ ), thus supporting hypothesis 2 . Hypothesis 3 , which stated that behavior-focused self-leadership strategies were negatively related to procrastination was also supported by the results $\left(\mathrm{b}=-0.31, \mathrm{t}_{(1436)}=-8.82, p\right.$ $=0.000)$. Regarding hypothesis 4 , it was assumed that the relationship between support from the environment 
and academic procrastination would be mediated by behavior-focused self-leadership strategies. The results, shown in Table 1 and Figure 2 supported the hypothesized mediation model. The analysis showed that the negative association between support from the environment and academic procrastination reduced when behavior- focused self-leadership strategies were introduced in the regression model $\left(\mathrm{b}=-0.06, \mathrm{t}_{(1436)}=-1.47, p=0.000\right)$. The total model explained $8 \%$ of academic procrastination $\left(R^{2}\right.$ $\left.=0.08 ; \mathrm{F}_{(5.1430)}=24.82, p<0.001\right)$. The variance difference explained for the model without the mediational effect of self-leadership was $5 \%\left(\Delta R^{2}=0.05\right)$.

Table 1

Direct and indirect effect of support from the environment on academic procrastination

\begin{tabular}{lcccccc}
\hline & \multicolumn{3}{c}{ Self-leadership - BFS } & \multicolumn{3}{c}{ Procrastination } \\
\hline Sex & Coef. & $t$ & $p \leq$ & Coef. & $t$ & $p \leq$ \\
Age & $\mathbf{0 . 1 4}$ & $\mathbf{4 . 0 0}$ & $\mathbf{0 . 0 0 0}$ & $\mathbf{- 0 . 2 2}$ & $\mathbf{- 4 . 4 5}$ & $\mathbf{0 . 0 0 0}$ \\
Holds a job & $\mathbf{0 . 0 0}$ & $\mathbf{0 . 3 2}$ & $\mathbf{0 . 7 4 8}$ & $\mathbf{- 0 . 0 0}$ & $\mathbf{- 2 . 0 0}$ & $\mathbf{0 . 0 4 5}$ \\
Support from the environment (direct effect) & 0.02 & 0.54 & 0.536 & -0.02 & -0.39 & 0.699 \\
Self-leadership - FC & $\mathbf{0 . 2 6}$ & $\mathbf{9 . 3 3}$ & $\mathbf{0 . 0 0 0}$ & $\mathbf{- 0 . 1 4}$ & $\mathbf{- 3 . 5 9}$ & $\mathbf{0 . 0 0 0}$ \\
Support from the environment (indirect effect) & & & & $\mathbf{- 0 . 3 1}$ & $\mathbf{- 8 . 8 2}$ & $\mathbf{0 . 0 0 0}$ \\
$\mathrm{R}^{2}$ (Direct effect) $=0.03$ & & & & $\mathbf{- 0 . 0 6}$ & $\mathbf{- 1 . 4 7}$ & $\mathbf{0 . 0 0 0}$ \\
$\mathrm{R}^{2}$ (Total effect) $=0.08$ & & & & & & \\
$\Delta \mathrm{R}^{2}=0.05$ & & & & & & \\
\hline
\end{tabular}

Note. ${ }^{* * *} p \leq 0.001 ; * * p \leq 0.05 ; * p \leq 0.010$.

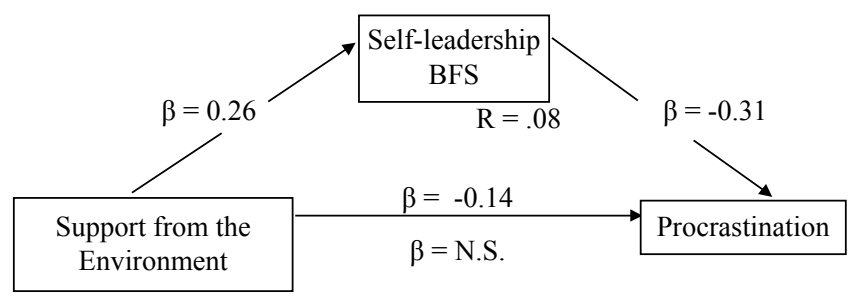

Figure 2. Conceptual hypothetical model.

\section{Discussion}

This study aimed to evaluate the mediational effect of behavior-focused self-leadership strategies in the relationship between support from the environment and academic procrastination. The evaluation of this relationship was investigated using the mediating role of behavior-focused self-leadership strategies, in the relationship between support from the environment and academic procrastination, after controlling sex, age and whether the individuals currently worked.

According to the social cognitive theory (Bandura, 1977), it was theorized and found as a result that self-regulation and self-leadership can be important regulatory mechanisms for procrastination. In addition, it was shown that support from the environment can influence academic procrastination directly and indirectly, when facilitated by student behaviorfocused self-leadership strategies. Thus, this is one of the innovative contributions to the scientific literature, as it showed how self-influence and self-motivation can interfere with changing undesirable behaviors, such as academic procrastination.

The new findings contribute to the understanding of academic procrastination antecedents. The results supported the hypothesized mediation model and are in line with the social cognitive theory, when it states that subjects are agents of their own development, and they intentionally interact with the circumstances of life (Bandura, 1977). That is, they self-regulate and self-organize, strategically shaping their behavior through their own leadership, influencing the way they act in different circumstances of life (Manz et al., 2016). Furthermore, they are also consistent with the self-regulation theory when it states that individuals' beliefs and their own abilities can influence their reactions to everyday events (Ryan \& Deci, 2000).

The correlation analysis showed that support from the environment was negatively associated with academic procrastination (hypothesis 1). These data confirmed the scientific literature presented, since support from the environment consists of the incentives that can be offered to students through classmates' or peers' language and behaviors in the classroom. In addition, the teacher's role also becomes relevant in this process, as it offers stimuli, disseminates information, provides feedback and guides content that will influence the learning process and task performance (Coelho Junior, da Silva Abbad \& de Lira Todeschini, 2005; Grunschel et al., 2018; Hen \& Goroshit, 2018).

Confirmation of hypothesis 2 corroborated previous studies proving that students' behavior can be influenced by support from the environment through interactions with classmates, development of activities, feedback received as well as by involvement with teachers (Coelho Junior, da Silva Abbad \& de Lira Todeschini, 2005; Manz et al., 2016). The positive association between support from the environment and behavior-focused self-leadership strategies confirms the importance of teachers' and classmates' roles in students' motivation as well as in their engagement with the activities provided in the classroom. Finally, the present 
study showed how the teacher's figure and the classroom scenario can positively influence perception in relation to their own behavior and how it affects the performance of the activities developed.

The findings in this study have confirmed previous studies showing that individuals who have strategies for controlling and organizing events in their lives are able to reduce procrastinating behavior (Balkis \& Duru, 2016; Grunschel et al., 2018; Job et al., 2015; Kadzikowska-Wrzosek, 2018; Rebetez et al., 2016; Ribeiro et al., 2014). In this study, it was possible to understand that behavior-focused self-leadership strategies enable individuals themselves to evaluate when, why and in what conditions certain behaviors occur and, from that, analyze the cause of the wasted or underused time so as to, then, change and act in desirable manner in relation to academic tasks (Manz et al., 2016). It is known that, in the academic or corporate sphere, there are activities and tasks that are unattractive, but necessary, which can be performed when using the self-leadership strategy associated with a sense of purpose and self-reward (Neck \& Manz, 2013; Neck et al. , 2019).

An environment characterized by autonomy can provide individuals with the freedom to apply natural reward strategies and engage in other autonomous behaviors, resulting in higher levels of satisfaction and motivation in performing tasks (Kotzé, 2018; Neck et al., 2019). Individuals who show self-leadership look for ways to direct their own activities through behavioral strategies, natural rewards and cognitive thoughts (Furtner, Tutzer, \& Sachse, 2018; Houghton \& Neck, 2002; Neck et al., 2019).

The behavioral dimensions of strategies focused on selfleadership behavior were reinforced in this study as a way to reduce procrastination through self-observation, self-goal setting, self-reward, and self-feedback for self-correction and self-support (Müller \& Niessen, 2018; Neck \& Manz, 2013; Manz et al., 2016; Panagopoulos \& Ogilvie, 2015).

Upon reaching the objective of this study, research advances in relation to previous investigations by providing empirical evidence that supports the importance of selfleadership in reducing procrastination. This result is in agreement with the findings by Neck and Houghton (2006), Manz et al. (2016) and Sims (2014), who advocate the predictive power of the self-leadership theory.

The present study sheds light on the development of interventions that can collaborate for individuals to become effective in performing their academic or labor activities, as well as on the conditions in which proactive or procrastination behaviors can occur. In addition, it emphasizes how people can learn, develop and adapt behavior-focused self-leadership skills, thus enabling their improvement in academic results (Neck \& Manz, 2013; Neck et al., 2019).

This study was based on a cross-sectional design, which does not allow inferences concerning the causality of the studied variables or the exploration of their effects over time. For such a procedure, it would be necessary to carry out a longitudinal study, since positive cycles can arise through the existence of relationships between self-leadership, support from the environment and academic procrastination over time. It is suggested that other studies adopt a longitudinal design to test these variables.

The literature review shows a scarcity of domestic studies on the subject, which makes it impossible to compare the results herein presented to those in other studies within the Brazilian context. Thus, it is suggested that the list of variables analyzed in this investigation be replicated for other samples in Brazil.

Another limitation to the study is related to its selfreported data, which can be a source of measurement bias. The objective of this investigation was to test a theoretical model, and the relationships addressed were not analyzed for different groups of students or distinguished in terms of programs, public and private institutions, program stages, regions of the country or shifts of school attendance. It is suggested that other studies should explore and analyze these relationships in order to expand theoretical understanding.

The results in this study highlight the importance of promoting a positive effect in the academic environment. Teachers can stimulate self-leadership learning by their students in order to increase strategies focused on behavioral changes. And from there, it is suggested that an analysis should be conducted on whether self-leadership would increase after encouraging and disseminating this topic, that is, by measuring individuals' self-leadership before and after they have access to the subject.

The empirical relationships explored provide new theoretical elements that can enrich the previous models by explaining academic procrastination. In addition, it provides useful information for further studies, exploring the role of self-leadership in academic settings. In summary, behaviorfocused self-leadership strategies play an important role in the relationship between support from the environment and academic procrastination. Therefore, the aim of the study was to investigate the extent to which academics procrastinate when they receive support from the environment (teachers and classmates) and how behavior-focused self-leadership strategies mediated such relationship. The study results confirmed that students stopped postponing important tasks when they received support from the environment, from teachers and classmates. In addition, this study showed that self-assessment and self-influence can change undesirable behaviors, such as the procrastination behavior, and define desirable behaviors that improve daily performance in academic tasks.

\section{Referências}

Bandura, A. (1977). Social learning theory. Englewood Cliffs, NJ: Prentice-Hall.

Balkis, M., \& Duru, E. (2016). Procrastination, selfregulation failure, academic life satisfaction, and affective well-being: Underregulation or misregulation form. European Journal of Psychology of Education, 31(3), 439-459. doi:10.1007/s10212-015-0266-5 
Browne, M. W., \& Cudeck, R. (1993). Alternative ways of assessing model fit. In K. A. Bollen \& J. S. Long (Eds.), Testing structural equation models (pp. 136-162). Newbury Park, CA: SAGE.

Coelho Junior, F. A., da Silva Abbad, G., \& de Lira Todeschini, K. C. (2005). Construção e validação de uma escala de suporte à aprendizagem no trabalho em uma instituição bancária brasileira. Revista Psicologia: Organizações e Trabalho, 5(2), 167-196. ISSN 1984-6657.

Ferrari, J. R., Harriott, J. S., Evans, L., Lecik-Michna, D. M., \& Wenger, J. M. (1997). Exploring the time preferences by procrastinators: Night or day, which is the one? European Journal of Personality, 11(3), 187-196. doi:10.1002/(SICI)1099-0984(199709)11:3<187::AIDPER287>3.0.CO;2-6

Furtner, M. R., Tutzer, L., \& Sachse, P. (2018). The mindful self-leader: Investigating the relationships between self-leadership and mindfulness. Social Behavior and Personality: An International Journal, 46(3), 353-360. doi:10.2224/sbp.6521

Geara, G. B., Hauck Filho, N., \& Teixeira, M. A. P. (2017). Construção da escala de motivos da procrastinação acadêmica [Construction of the motive scale of academic procrastination]. Psico, 48(2), 140-151. doi:10.15448/1980-8623.2017.2.24635

Grunschel, C., Patrzek, J., Klingsieck, K. B., \& Fries, S. (2018). "I'll stop procrastinating now!' Fostering specific processes of self-regulated learning to reduce academic procrastination. Journal of Prevention \& Intervention in the Community, 46(2), 143-157. doi:10.1080/10852352. 2016.1198166

Hen, M., \& Goroshit, M. (2018). Prevention and intervention for academic procrastination in academic communities. Journal of Prevention \& Intervention in the Community, 46(2), 113-116. doi:10.1080/10852352. 2016.1198149

Houghton, J. D., \& Neck, C. P. (2002). The revised self-leadership questionnaire: Testing a hierarchical factor structure for self-leadership. Journal of Managerial Psychology, 17(8), 672-691. doi:10.1108/02683940210450484

Job, V., Walton, G. M., Bernecker, K., \& Dweck, C. S. (2015). Implicit theories about willpower predict self-regulation and grades in everyday life. Journal of Personality and Social Psychology, 108(4), 637-647. doi:10.1037/ pspp0000014

Kadzikowska-Wrzosek, R. (2018). Self-regulation and bedtime procrastination: The role of self-regulation skills and chronotype. Personality and Individual Differences, 128, 10-15. doi:10.1016/j.paid.2018.02.015

Klingsieck, K. B. (2013). Procrastination: When good things don't come to those who wait. European Psychologist, 18(1), 24-34. doi:10.1027/1016-9040/a000138
Kotzé, M. (2018). The influence of psychological capital, self-leadership, and mindfulness on work engagement. South African Journal of Psychology, 48(2), 279-292. doi:10.1177/0081246317705812

Manz, C., Houghton, J. D., Neck, C. P., Fugate, M., \& Pearce, C. (2016). Whistle while you work: Toward a model of emotional self-leadership. Journal of Leadership \& Organizational Studies, 23(4), 374-386. doi:10.1177/1548051816655993

Miles, J., \& Shevlin, M. (2001). Applying regression and correlation: A guide for students and researchers. London, United Kingdom: SAGE.

Müller, T., \& Niessen, C. (2018). Self-leadership and selfcontrol strength in the work context. Journal of Managerial Psychology, 33(1), 74-92. doi:10.1108/JMP04-2017-0149

Neck, C. P., \& Houghton, J. D. (2006). Two decades of self-leadership theory and research: Past developments, present trends and future possibilities. Journal of Managerial Psychology, 21(4), 270-295. doi:10.1108/02683940610663097

Neck, C. P., \& Manz, C. C. (2013). Mastering self-leadership: Empowering yourself for personal excellence (6th ed.). Upper Saddle River, NJ: Prentice Hall.

Neck, C. P., Manz, C. C., \& Houghton, J. D. (2019). Selfleadership: The definitive guide to personal excellence. Los Angeles, CA: SAGE.

Panagopoulos, N. G., \& Ogilvie, J. (2015). Can salespeople lead themselves? Thought self-leadership strategies and their influence on sales performance. Industrial Marketing Management, 47, 190-203. doi:10.1016/j. indmarman.2015.02.043

Preacher, K. J., \& Hayes, A. F. (2008). Asymptotic and resampling strategies for assessing and comparing indirect effects in multiple mediator models. Behavior Research Methods, 40(3), 879-891. doi:10.3758/BRM.40.3.879

Podsakoff, P. M., MacKenzie, S. B., \& Podsakoff, N. P. (2012). Sources of method bias in social science research and recommendations on how to control it. Annual Review of Psychology, 63, 539-569. doi:10.1146/ annurev-psych-120710-100452

Rebetez, M. M. L., Rochat, L., Barsics, C., \& Van der Linden, M. (2016). Procrastination as a self-regulation failure: The role of inhibition, negative affect, and gender. Personality and Individual Differences, 101, 435-439. doi:10.1177/0033294117720695

Ribeiro, F., Avelino, B. C., Colauto, R. D., \& Casa Nova, S. P. C. (2014). Comportamento procrastinador e desempenho acadêmico de estudantes do curso de Ciências Contáveis [Procrastinator behavior and academic performance of students of the Countable Science course]. Advances in Scientific and Applied Accounting, 7(3), 386-406. doi:10.14392/asaa.2014070304 
Ryan, R. M., \& Deci,E.L.(2000). Self-determination theory and the facilitation of intrinsic motivation, social development and well-being. American Psychologist, 55(1), 68-78. doi:10.1037110003-066X.55.1.68

Sims, C. M. (2014). Self-regulation coaching to alleviate student procrastination: Addressing the likeability of studying behaviours. International Coaching Psychology Review, 9(2), 147-164.

Visser, L., Korthagen, F. A., \& Schoonenboom, J. (2018). Differences in learning characteristics between students with high, average, and low levels of academic procrastination: Students' views on factors influencing their learning. Frontiers in Psychology, 9, 808. doi:10.3389/fpsyg.2018.00808

Vohs, K. D., \& Baumeister, R. F. (2004). Understanding selfregulation: An introduction. In R. F. Baumeister \& K. D. Vohs (Eds.), Handbook of self-regulation: Research, theory, and applications (pp. 1-9). New York, NY: Guilford.

Yockey,R.D.(2016).Validationoftheshortformoftheacademic procrastination scale. Psychological Reports, 118(1), 171-179. doi: $10.1177 / 0033294115626825$

Tais Guedes de Melo is a doctoral student in psychology at Pontifícia Universidade Católica de Goiás, Goiânia-GO, Brazil.

Helenides Mendonça is a Professor at Pontifícia Universidade Católica de Goiás, Goiânia-GO, Brazil.

\section{Authors' Contribution:}

All authors have made substantial contributions to the conception and design of this study, to data analysis and interpretation, to the manuscript revision and approval of its final version. All the authors assume public responsibility for content of the manuscript.

Received: Oct. 19, 2018

1st Revision: Mar. 08, 2019

2nd Revision: Jun. 19, 2019

Approved: Jul. 15, 2019

How to cite this article:

Melo, T. G. \& Mendonça, H. (2020). Academic procrastination: Relationships with support from the environment and self-leadership. Paidéia (Ribeirão Preto), 30, e3038.doi:https://doi.org/10.1590/1982-4327e3038 